Article

\title{
Synthesis of Silver Nanoparticles by Green Method Stabilized to Synthetic Human Stomach Fluid
}

\author{
Ayman M. Atta ${ }^{1,2, *}$, Hamad A. Al-Lohedan ${ }^{1}$ and Abdelrahman O. Ezzat ${ }^{1}$
}

1. Surfactants Research Chair, Department of Chemistry, College of Science, King Saud University, P.O.Box 2455, Riyadh 11451, Saudi Arabia; E-Mails: hlohedan@ksu.edu.sa (H.A.A.-L.); oa_ezzat@yahoo.com (A.O.E.)

2. Petroleum Application Department, Egyptian Petroleum Research Institute, Cairo 11727, Egypt

* Author to whom correspondence should be addressed; E-Mail: aatta@ksu.edu.sa; Tel.: +96-611-467-5998; Fax: +96-611-467-5992.

Received: 22 April 2014/in revised form: 20 May 2014/Accepted: 21 May 2014/

Published: 23 May 2014

\begin{abstract}
Silver nanoparticles (Ag NP) have been attracted much attention in recent years in biomedical applications due to their antimicrobial activity, but their drawbacks include toxicity and instability to aqueous hydrochloric acid solutions. Ag NPs have now been successfully prepared by a simple and "green" synthesis method by reducing $\mathrm{Ag}^{+}$ions in the presence of modified poly(vinyl alcohol) thiol (PVA-SH) in aqueous acidic solution. In this respect, Ag NPs were stabilized by coating different types of citrate-reduced Ag NPs with different weight ratios (1-3 Wt. \%) of PVSH derivatives. The as-prepared Ag NPs were characterized using UV-Visible, high resolution transmission electron microscopy/ energy dispersive X-ray spectroscopy (TEM/EDS), dynamic light scattering (DLS) and X-ray powder diffraction (XRD) combined with Rietveld analysis. The changes in size, shape, and hydrodynamic diameter of Ag NPs after different duration exposure to synthetic stomach fluid (SSF) and1 $\mathrm{M} \mathrm{HCl}$ were determined using TEM, XRD and UV-Visible analyses. The data indicated that these Ag NPs possessed high stability to SSF for more than 90 days, which was not previously reported in the literature.
\end{abstract}

Keywords: silver nanoparticles; poly(vinyl alcohol)thiol; aqueous acidic solution; citrate reducing agent 


\section{Introduction}

Production of advanced materials from nanomaterials is the main goal of nanotechnology. Silver nanoparticles (Ag NPs) have attracted tremendous interest due to their applications in bio-sensing [1], their antimicrobial activity [2] and use in biomedical treatments [3]. Ag NPs are typically prepared by reducing silver ions using toxic reducing agents, organic solvents, or non-biodegradable stabilizing agents, which makes them therefore potentially dangerous to the environment and biological systems [4]. The absorption of ingested colloidal silver has been examined in humans [5,6], but neither the absorbed form of silver (e.g., $\mathrm{Ag} \mathrm{NP}, \mathrm{Ag}^{+}$) nor the physical and chemical characteristics of the silver colloid during transit through the gastrointestinal tract were estimated [7]. Some data on the fate and effects of ingested Ag NPs have been discussed in other species. Intravenous administration or ingestion of very high doses of colloidal silver in rats results in organ failure and animal death [8,9]. Although such studies are useful, they may not fully account for the physiological differences between humans and rodents such as the fact that the $\mathrm{pH}$ of gastric fluid differs markedly between humans $(\mathrm{pH} 1.5)$ and mice $(\mathrm{pH} 3)$ [10,11]. This approach may be especially germane since both the synthetic methods and the mode of surface stabilization affect the dependence of surface charge and aggregation behavior of Ag NPs on $\mathrm{pH}$ and the ionic environment [12].

A literature survey indicated the advantages and limitations of the different methods of preparation of nanocomposite materials. In this respect, the green synthesis of metal nanocomposites has attracted great attention to develop new environmentally friendly technologies for materials science. The biosynthesis of nanoparticles has been proposed as a cost effective environmental friendly alternative to chemical and physical methods. There have been several attempts to prepare Ag NPs using plants [13], aqueous sorghum bran extracts [14] and microorganisms [15] as reducing agent. Well-dispersed and ultrafine metal nanoparticles, based on transition metals, have attracted great attention because of their superior thermodynamic and physicochemical properties. Pillai and Kamat [16] investigated the factors that controlled the size and shape of Ag NPs produced by the citrate reduction method but they did not solve the environmental stability problems. Cheng et al. [17] examined the effect of sunlight on the stability and toxicity of 6 and $25 \mathrm{~nm} \mathrm{Ag} \mathrm{NPs} \mathrm{coated} \mathrm{with} \mathrm{gum} \mathrm{Arabic} \mathrm{and} \mathrm{PVP.} \mathrm{They} \mathrm{reported} \mathrm{that,}$ under sunlight irradiation, all of these nanoparticles irreversibly aggregated into clumps of different degrees depending on the surface coating. A widely used approach has been to attach ligands (either small molecules or polymers) to the nanoparticle surface. Moreover, a vast number of nanoparticle-ligand systems has been reported to prepare environmental stabilized Ag NPs, based on various groups that are capable of binding to metal surfaces: phosphonic acid [18], aminocellulose as a combined reducing and capping reagent [19], a bespoke multidentate polymer with multiple surface-seeking groups and hydroxyl functionalities decorating their side-chains [20], chitosan [21], cysteine [22], amine-terminated generation poly(amidoamine) dendrimers [23] and PAA [24]. Useful coatings for biomedical application and delivery of Ag NPs, [25-29] based on glutathione, thiols, disulfides, thioethers, thioesters, thiocarbonates, and thiocarbamates are used in the preparation of metal nanoparticles. Because the bioavailability of ingested Ag NPs will likely depend on the aggregation state and chemical properties of the particles after modification in the acidic environment of the stomach, the primary objective of this preliminary study was to prepare in good yield highly stabilized, monodispersed, Ag NPs capped with modified PVA. A promising alternative method to prepare highly 
dispersed silver nanomaterials is the production of nanocomposites from highly dispersed self-assembled silver nanoparticles. In this respect, the $\mathrm{OH}$ groups of PVA were converted to $\mathrm{SH}$ groups to enhance the reduction efficiency of the citrate reducing agent used and to increase the yield of the Ag NPs. A study of the stability of the prepared Ag NPs in aqueous $\mathrm{HCl}$ solution and synthetic stomach fluid was another goal of the present work.

\section{Results and Discussion}

The goal of the present work was to develop a new sustainable synthetic method that combines many of the desired features for silver composite nanoparticles to overcome the limitations of the reported methods to prepare silver nanomaterials such as the use of hazardous materials in their synthesis and purification. In any green synthesis of nanoparticles, there are three green chemistry principles that should be investigated: (i) use of a green solvent such as water; (ii) choice of an eco-friendly and benign reducing agent; and (iii) choice of a nontoxic material such as PVP or PVA as a stabilizer. To date, most of the published methods to prepare nanomaterials are based on using organic materials due to the hydrophobicity of the stabilizing agents used, such as natural polymers.

The stability of the Ag NPs to the environment, polydispersity and low yield are the major disadvantages of these methods [30,31]. Novel electrochemical and chemical methods developed to prepare nontoxic Ag NPs capped either with surfactants, poly (vinyl alcohol) (PVA), poly (acrylic acid) (PAA) and poly (vinyl pyrrolidone) (PVP) as capping agents have been reported [32-34]. Using a polymer as a matrix for preparing metallic nanoparticles, the repeat unit of the polymer should have polar functional group to chelate with the metallic nanomaterials. The advantages of these methods are the preparation of Ag NPs with high purity and the possibility of a precise particle size control achieved by adjusting the current density or applied potential. However, the instability of the prepared capped Ag NPs to environmental conditions such as sunlight, chemical reagents, $\mathrm{pH}$ and the increased toxicity due to slow dissolution releasing silver ions during storage are still unsolved problems [35]. The present work applied a new method to prepare a polymer thiol self-assembly to form monolayers on silver surfaces by the spontaneous assembly of organic modified polymer molecules on core-shell substrates. Two main routes are usually followed to produce thiol-capped Ag NPs. The first one consists in the synthesis of NPs in the presence of the desired coating agents. This method has a drawback in that the presence of the coating agents often influences the synthetic procedure and produces NPs with variable dimensions depending on the concentration and nature of the coating agents [36] and on the reaction conditions [2]. The alternative method consists of the post-functionalization of previously synthesized NPs with the desired and controlled dimensions and shapes. This path is preferred when the desired surface properties need to be correlated to specific size and shape features. The main objective of the present work was to develop a simple and low cost efficient route to obtain thiol derivatives of poly(vinyl alcohol) for use as a stabilizing agent for silver ions and as efficient dispersants for silver zero-valent (Ag) nanoparticles. It was expected that the proposed synthetic route would allow the control of size, yields, and chemical stability of the resulting Ag NPs. The mechanism of the synthesis is based on the reduction of silver nitrate solution in the presence of organic modified thiol derivatives of poly(vinyl alcohol) (PVA-SH) as described in Scheme 1. 
Scheme 1. Reduction of $\mathrm{AgNO}_{3}$ in the presence of PVA-SH and sodium citrate solution.

$$
\begin{gathered}
\mathrm{Ag}^{I} \mathrm{NO} 3+\mathrm{PVA}-\mathrm{SH} \rightarrow\left(\mathrm{Ag}^{\mathrm{I}} \mathrm{PVA}-\mathrm{S}\right)_{n} \\
\left(\mathrm{Ag}^{\mathrm{I} P V A-S)_{n}}+\mathrm{Na}_{3} \mathrm{C}_{6} \mathrm{H}_{5} \mathrm{O}_{7} \stackrel{(\text { trisodium citrate })}{\longrightarrow} \mathrm{Ag}_{x}(\mathrm{PVA}-\mathrm{S})_{y}+\mathrm{C}_{5} \mathrm{H}_{6} \mathrm{O}_{5} \text { (3-ketoglutaric acid }\right) \\
+3 \mathrm{NaNO}_{3}+\mathrm{CO}_{2}
\end{gathered}
$$

$\mathrm{Ag}(\mathrm{I}) \mathrm{NO}_{3}$ is coated by thiols to yield a (Ag PVA-SH) polymer. Aqueous $\mathrm{Na}_{3} \mathrm{C}_{6} \mathrm{H}_{5} \mathrm{O}_{7}$ is added to reduce the Ag PVA-SH, and the $\mathrm{Ag}_{\mathrm{x}}(\mathrm{PVA}-\mathrm{S})_{\mathrm{y}}$ nanoparticles are formed. The formation of self-assembled silver nanoparticles is illustrated in Scheme 2.

Scheme 2. Preparation of self-assembled Ag NPS in the presence of PVA-SH.
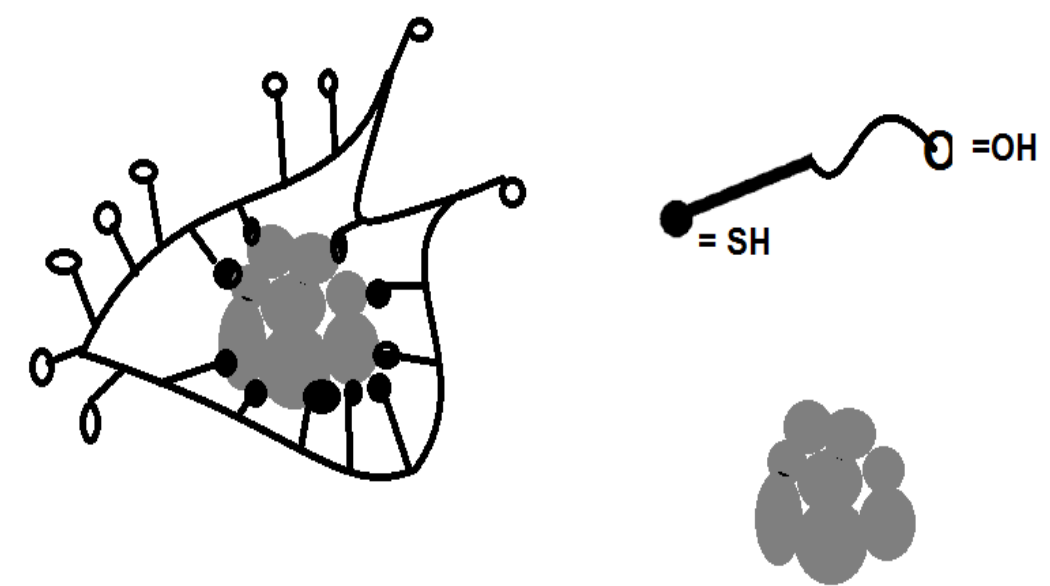

Silver core

A coating procedure that allows for the stabilization of Ag NPs with biological capping agents featuring thiol moieties like glutathione (GSH) and cysteine (CYS) was previously reported [25,37]. The data showed that the molar composition of the capped colloids was in $\mathrm{Ag}_{1.00} \mathrm{GSH}_{0.03}$ and $\mathrm{Ag}_{1.00} \mathrm{CYS}_{0.09}$ [25]. Furthermore, it was found that GSH-coated Ag NPs were soluble at $\mathrm{pH} 7$ in highly saline media, and could be used for antibacterial purposes [37].

\subsection{Chemical Structure of PVA-SH}

It was previously reported that the toxicity of gold nanocluster was eliminated using of thiolate ligand based on polyethylene glycol thiolate [38]. Moreover it is well known that PVA is a nontoxic green polymer. In this respect, the chemical structure of PVA will be modified to thiolate to use as capping agent to reduce the toxicity of the silver nanoparticles. It is well known that the chemical structure of the thiols used to cap the silver nanoparticles plays an important role for preparing monodisperse nanoparticles with controlled shapes and size suitable for biological applications. The present work aims to modify the chemical structure of PVA to convert the hydroxyl groups to thiol groups (PVA-SH). The reaction procedure is illustrated in Scheme 3. 
Scheme 3. Synthesis of PVA-SH.

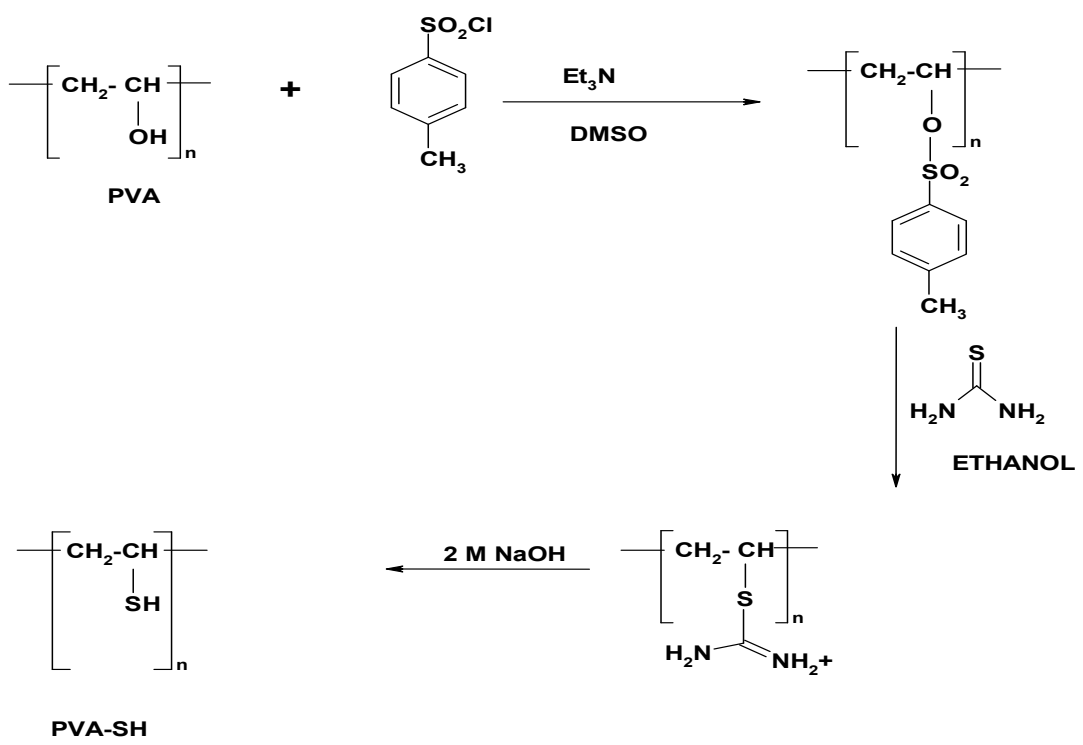

The chemical structure of PVA-SH was confirmed by IR and ${ }^{1} \mathrm{H}-\mathrm{NMR}$ spectroscopy as illustrated in Figures 1 and 2.

Figure 1. FTIR spectra of (a) PVA and (b) PVA-SH.
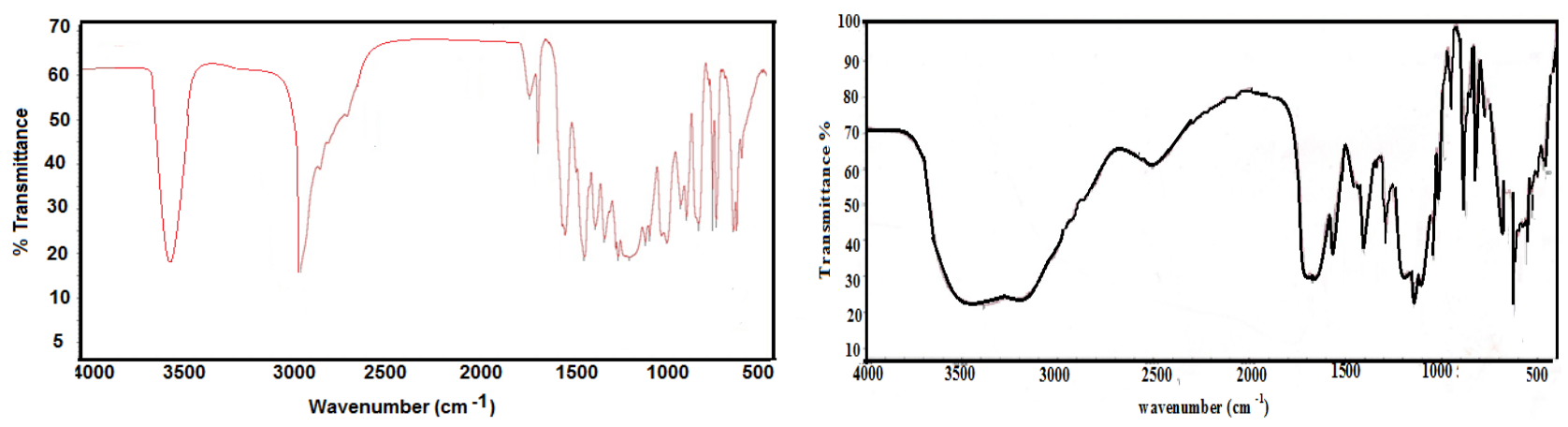

Figure 2. ${ }^{1} \mathrm{H}-\mathrm{NMR}$ Spectra of (a) PVA and (b) PVA-SH.
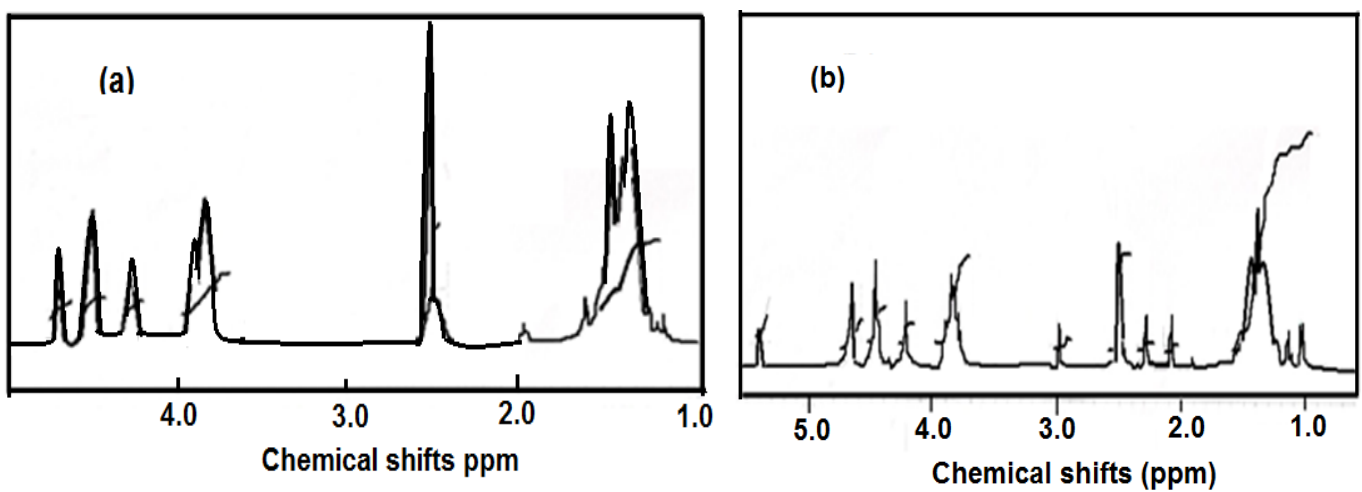

The IR spectrum of PVA-SH (Figure 1) indicated the appearance of new band at $2500 \mathrm{~cm}^{-1}$ (SH stretching) besides a strong absorption at $3500 \mathrm{~cm}^{-1}$ (OH-stretching band). This result indicated that the hydroxyl groups of PVA were not completely converted to thiols. ${ }^{1} \mathrm{H}-\mathrm{NMR}$ analysis was used to confirm the chemical structure of PVA-SH and to determine the $\%$ of conversion of $\mathrm{OH}$ groups to 
$\mathrm{SH}$ groups. The signals at 4.5, 3.8, $2.5 \mathrm{ppm} 1.45 \mathrm{ppm}$ and $1.33 \mathrm{ppm}$ (Figure 2a) were assigned to $\mathrm{CH}-\mathrm{OCO}$ attached to the vinyl acetate of PVA, $\mathrm{CH}$ protons (attached to $\mathrm{OH}$ groups), $\mathrm{OH}$, backbone methylene and $\mathrm{COCH}_{3}$, respectively. These peaks appeared in spectrum of PVA-SH, Figure 2b, where moreover, new peaks appeared at 2.29 and $5.4 \mathrm{ppm}$ which were attributed to $\mathrm{CH}_{2}-\mathrm{S}$ and $\mathrm{SH}$, respectively. The \% of $\mathrm{OH}$ conversion of PVA to $\mathrm{CH}_{2} \mathrm{SH}$ was estimated by comparing the integration signal ratios between the $\mathrm{OH}$ proton at $2.5 \mathrm{ppm}$ and the $\mathrm{SH}$ proton at $5.4 \mathrm{ppm}$. The data indicated that approximately of $40 \%$ of the $\mathrm{OH}$ groups were converted to $\mathrm{SH}$ groups.

\subsection{Acid Stability of Citrate Ag NPs}

In humans, the bioavailability of ingested Ag NPs will likely depend on a number of factors including particle size distribution, shape, stabilizer use, and any transformation processes that occur during transit through the gastrointestinal tract. The bioavailability of Ag from these Ag-containing materials will also depend on the interactions between this mixture of Ag-containing species and the absorptive surfaces of the gastrointestinal tract [39]. The aggregation of Ag NPs leads to inhibition of the bioactivity of silver nanoparticles. Hence, ingested Ag NPs may be aggregated or converted to $\mathrm{AgCl}$ when reacted with SSF. In this respect, the reactivity of $\mathrm{Ag}$ Nps towards SSF was investigated at three different molar concentrations of aqueous $\mathrm{HCl}(0.1,0.5$ and $1 \mathrm{M})$ in the presence of $0.4 \mathrm{M}$ of glycine at $1 \mathrm{~h}$ time intervals. Several characteristic methods were used to elucidate the formation of the silver nanoparticles such as TEM or UV-Vis analyses. A set of TEM images, and UV-Vis absorption spectra of the dispersed citrate Ag NPs in water is presented in Figure 3.

Figure 3. Set of images for silver nanoparticles: (a) TEM image of the citrate AgNP and (b) its UV-Vis absorption spectrum.
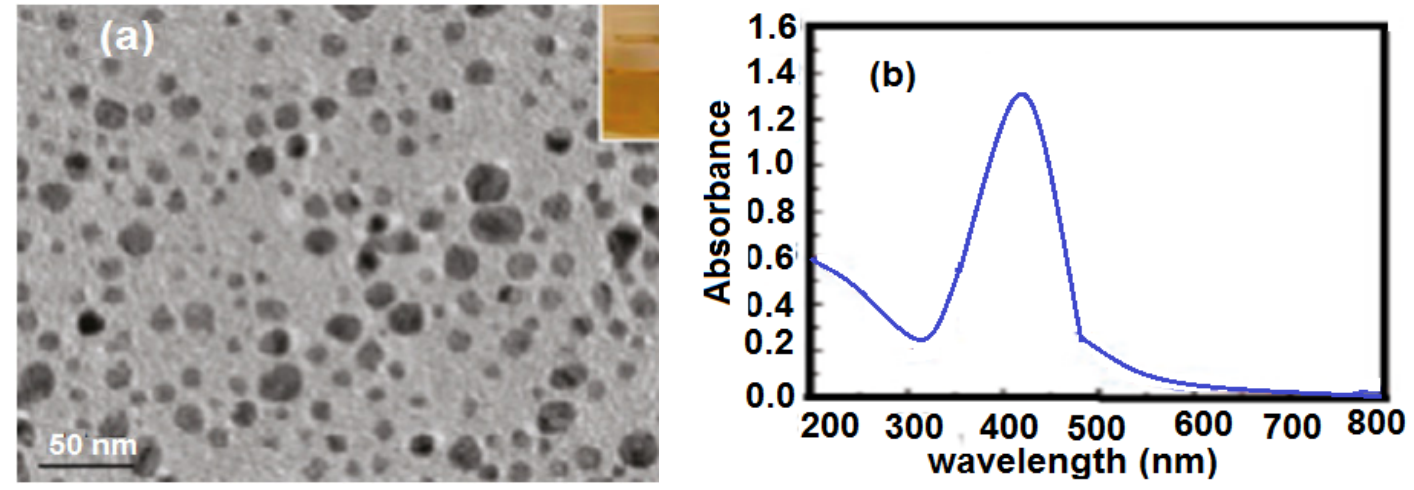

As can be seen from this figure, these nanoparticles are relatively monodisperse in size. The average particle size of the Ag NPs is $6 \mathrm{~nm}$. The formation of Ag Nps is also evident from the UV-Vis absorption spectra (Figure 4b) exhibiting a relatively intense surface plasmon resonance (SPR) at $405 \mathrm{~nm}$.

Figure 4 shows a set of digital images of the suspensions and the UV-Vis absorption spectra of $\mathrm{Ag}$ NPs under $0.1 \mathrm{M} \mathrm{HCl}$ conditions. A comparison of these digital images indicates that the $0.1 \mathrm{M} \mathrm{HCl}$ affected the stability of citrate Ag NPs that gradually changed the color from yellow to green to turbid white and precipitated to the bottom of the vial. On the other hand, the stability data of citrate Ag NPs can be also supported by the UV-Vis absorption spectra which were acquired over time (Figure $4 \mathrm{~b}$ ). 
Figure 4. Citrate Ag NPs (a) digital photo (b) their UV-Vis absorption spectra at timed intervals in $0.1 \mathrm{M} \mathrm{HCl}$.

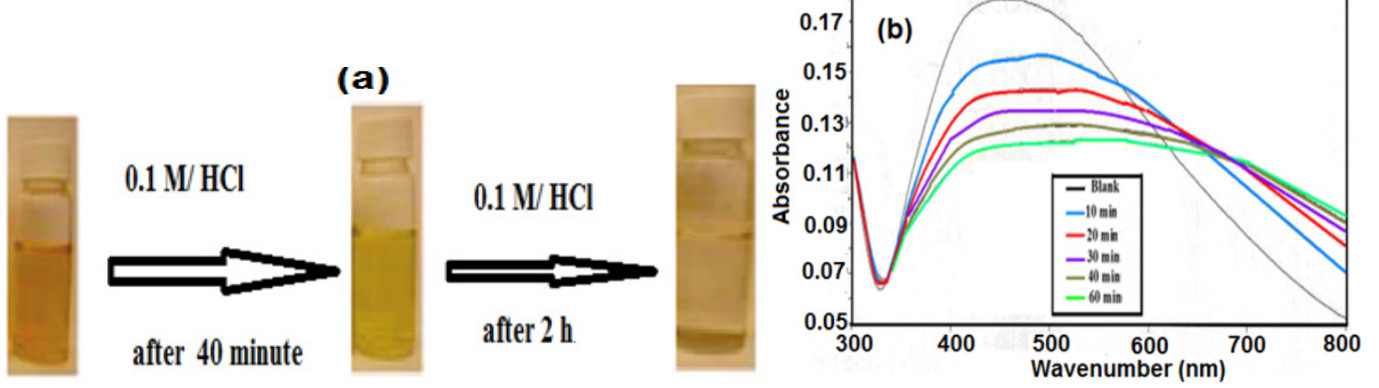

The intensity of all the SPR peaks decreased as the time of exposure of the citrate-stabilized nanoparticles to $0.1 \mathrm{M} \mathrm{HCl}$ increased, which indicates the aggregations of Ag-NPs increased under $0.1 \mathrm{M}$ aqueous $\mathrm{HCl}$ conditions. The SPR peak of citrate Ag NPs disappeared completely after $90 \mathrm{~min}$. The decrease might be caused by the gradual increase in average particle diameter due to the Ostwald ripening process.

The spectrum of the citrate Ag NPs in $0.1 \mathrm{M} \mathrm{HCl}$ is red shifted and broadened compared with the spectrum of colloidal solution in distilled water. This observation indicated that the Ag NPs in $0.1 \mathrm{M}$ $\mathrm{HCl}$ undergo agglomeration to bigger particles or implied that a thin layer of silver oxide $\left(\operatorname{Ag}_{2} \mathrm{O}\right)$ formed on the surface of silver nanoparticles [40]. The shoulder peak around $420 \mathrm{~nm}$ was indicative of the presence of $\mathrm{Ag}$ NPs without $\mathrm{Ag}_{2} \mathrm{O}$ layers, and the absorption band at ca. $450 \mathrm{~nm}$ suggested the existence of $\mathrm{Ag} / \mathrm{Ag}_{2} \mathrm{O}$ core-shell structures. The intensity of the peak implied the amount of the corresponding structure in the sample, and the thickness of $\mathrm{Ag}_{2} \mathrm{O}$ layers on the $\mathrm{Ag}$ surface could be inferred from the position of the absorption band at ca. 450-470 nm. The formation of $\mathrm{Ag} / \mathrm{Ag}_{2} \mathrm{O}$ core-shell or aggregation of citrate Ag NPs in acidic condition was examined by XRD analysis.

Figure 5. XRD patterns of citrate $\operatorname{AgNP}$ (a) before dispersion in $0.1 \mathrm{M} \mathrm{HCl}$ and (b) after dispersion in $0.1 \mathrm{M} \mathrm{HCl}$ for $40 \mathrm{~min}$.
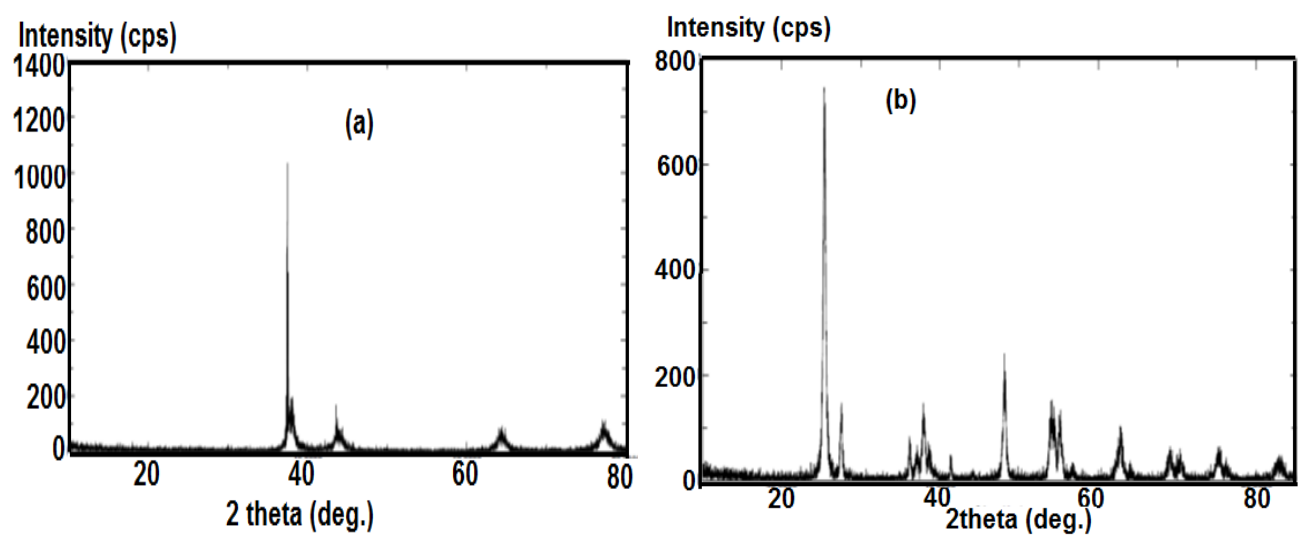

The XRD patterns of citrate Ag NPs before and after dispersion in $0.1 \mathrm{M} \mathrm{HCl}$ are presented in Figure 5. The XRD pattern of citrate Ag NPs in $0.1 \mathrm{M} \mathrm{HCl}$ (Figure 5b) suggested that the formation of silver oxide and silver chloride particles. The structure is cubic shape, which is in good agreement with the reported data of $\mathrm{AgCl}$ [41]. The broadening of peaks indicates the very small sizes of $\mathrm{Ag}$ crystallites. The formation of metallic silver nanoparticles crystallized in the face centered cubic (fcc) 
structure appeared in citrate $\mathrm{Ag} \mathrm{NPs}$ before dispersion in $0.1 \mathrm{M} \mathrm{HCl}$ (Figure 5a) $[9,41]$. Using the Scherrer formula $D=n \lambda / \beta \cos \theta$, where $D$ is the crystallite size, $n$ is a constant $(0.9$ assuming that the particles are spherical), $\lambda$ is the wavelength of the $\mathrm{X}$-ray radiation, $\beta$ is the line width (obtained after correction for the instrumental broadening) and $\theta$ is the angle of diffraction we have calculated the crystal-lite size of the $\mathrm{Ag}_{2} \mathrm{O}$ particles. The average particle size obtained from XRD data is found to be changed from $10 \mathrm{~nm}$ to $27.90 \mathrm{~nm}$.

\subsection{Stability of Ag/PVA-SH NPs to SSF}

A recent study that administered Ag NPs orally in rats for 28 days evidenced hepatotoxicity (evidenced the formation of serum cholesterol and alkaline phosphatase enzyme) [42]. No physiological differences between humans and rodents were reported, although it was previously reported that the $\mathrm{pH}$ of gastric fluids was 1.5 in human and 3 in the mouse [10,11]. In this respect, it will be highly effective to investigate the particle alterations in an in vitro system that more closely resembles the human stomach than the mouse stomach. The present work used synthetic stomach fluid (SSF) to investigate the physical and chemical changes of the silver nanoparticles. SSF was prepared from deionized water, glycine $(0.4 \mathrm{M})$, and $\mathrm{HCl}(0.42 \mathrm{M})$ to control the $\mathrm{pH}$ at 1.5 . There are two protection mechanisms used to investigate the stability of aqueous solutions of Ag NPs. The first mechanism is based on the balance between attractive and repulsive forces of the nanoparticles which controlls the thickness of the adsorbed layer, which is, in the case of polymers, dependent not only on the chain length but also on the adsorption mode. The second mechanism of the dispersion system stabilization is based on electrostatic repulsion. In this respect, PVA-SH groups are bonded stronger on the Ag NPs' surface through the sulfur atom as described in Scheme 2. The Ag NPs used in this study were citrate Ag NPs, and Ag NPs coated with PVA-SH used to investigate the reactivity of Ag NPs toward $\mathrm{HCl}$ solutions. They were freshly prepared and purified with an ultracentrifuge as described in the Experimental Section. The yield \% data for the formation of Ag NPs in the absence and presence of PVA-SH 0.5, 1, 2, 3 (Wt. \%) was 55, 65, 80 and 95\%, respectively. These data indicated that the productivity for production of Ag NPs increased with the increment of PVA-SH.

The reactivity of $\mathrm{Ag}$ Nps towards SSF was investigated from $1 \mathrm{~h}$ to 90 days exposure time intervals. The stability of dispersed Ag Nps/PVA-SH in $1 \mathrm{M} \mathrm{HCl}$ and $0.4 \mathrm{M}$ of glycine was estimated using TEM, particle size distribution and UV spectroscopy for 90 days. UV-Vis absorption spectra of Ag NPs/PVA-SH at interval times were selected and are presented in Figure 5.

Figure $6 \mathrm{a}$ is a set of the UV-Vis absorption spectra which were acquired over time under $0.5 \mathrm{M}$ aqueous $\mathrm{HCl}$ and $0.4 \mathrm{M}$ glycine conditions. The absorption peak of Ag NPs at $405 \mathrm{~nm}$ decreased without a blue or red shift and its broadness increased after $1 \mathrm{~h}$, perhaps caused by a gradual increase in the average particle diameter due to the Ostwald ripening process. However, the coating on the NPs clearly has a strong effect on their stability. The preservation of the nano-dimensional character of the system modified by Ag/PVA-SH, with limited particle interactions, is also evident from the UV-Vis absorption spectra (Figure 6) exhibiting a relatively intense surface plasmon peak at $405 \mathrm{~nm}$. Figure 5 shows the high stability of silver-PVA-SH, even up to 90 days. The stability of coated Ag NPs in $1 \mathrm{M}$ $\mathrm{HCl}$ was investigated and presented in Figure $5 \mathrm{~b}$. The data indicated that the stability decreased with 
increasing concentration of $\mathrm{HCl}$. The data indicated that $\mathrm{Ag} / \mathrm{PVA}-\mathrm{SH}$ nanoparticles are stable for 7 days in $1 \mathrm{M} \mathrm{HCl}$ and $0.4 \mathrm{M}$ glycine aqueous solution.

Figure 6. UV-Vis absorption spectra of Ag/PVA-SH at interval times in (a) SSF (0.5 M and $0.4 \mathrm{M}$ glycine) and (b) $1 \mathrm{M} \mathrm{HCl}$ and $0.4 \mathrm{M}$ glycine.
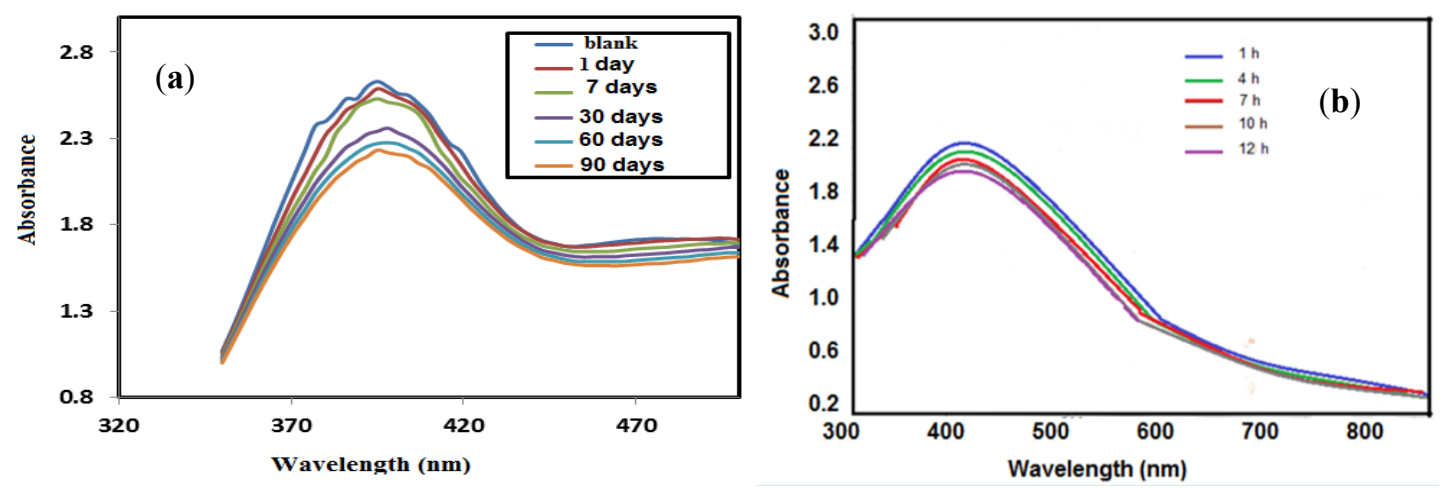

The particle size distribution of Ag NPs/PVA-SH in the presence of $1 \mathrm{M} \mathrm{HCl}$ and $0.4 \mathrm{M}$ of glycine was estimated using dynamic light scattering (DLS) to evaluate the variation in particle size distribution up to 1 week. Figure 7 shows that the particle size of the Ag NPs/PVA-SH ranged between 5 and $20 \mathrm{~nm}$.

Figure 7. Particle size distribution of $\mathrm{Ag} / \mathrm{PVA}-\mathrm{SH}$ in $1 \mathrm{M} \mathrm{HCl}$ and $0.4 \mathrm{M}$ of glycine at interval times (a) $1 \mathrm{~h}$, (b) $24 \mathrm{~h}$ and (c) 7 days.

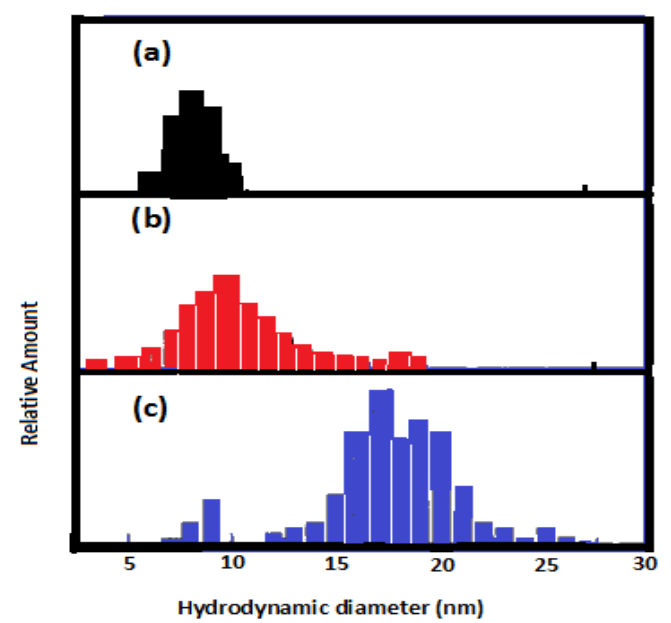

The particle size changed to be uniform and between $8-12 \mathrm{~nm}$ after $24 \mathrm{~h} 1 \mathrm{M} \mathrm{HCl}$ exposure (Figure $7 \mathrm{~b}$ ). The particle size distribution increased after exposure to $1 \mathrm{M} \mathrm{HCl}$ for 7 days (Figure 7c). The data indicated that the polydispersity of PVA-SH silver nanoparticles changed by aggregation after exposure to aqueous solution of $1 \mathrm{M} \mathrm{HCl}$ and $0.4 \mathrm{M}$ of glycine for 7 days. The particle size diameter increased to be $15-30 \mathrm{~nm}$.

TEM data illustrated in Figures $8 \mathrm{a}-\mathrm{c}$ indicates the same results as DLS. The average particle size of the Ag NPs changed from $6 \mathrm{~nm}$ to $25 \mathrm{~nm}$. The aggregation of citrate-stabilized nanoparticles was observed after exposure of $0.1 \mathrm{M} \mathrm{HCl}$ for $20 \mathrm{~min}$ (Figure 7d). 
Figure 8. TEM image of Ag NP (a) coated with PVA-SH, after exposure to $1 \mathrm{M} \mathrm{HCl}$ and $0.4 \mathrm{M}$ of glycine (b) for 1 week, (c) for 3 months and (d) citrate Ag NP after exposure to $0.1 \mathrm{M} \mathrm{HCl}$ for $1 \mathrm{~h}$.

(a)

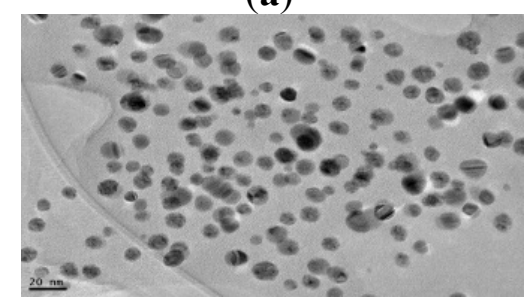

(c)

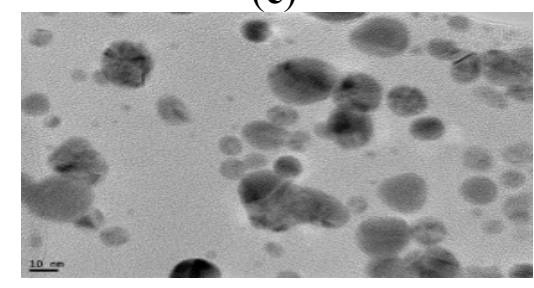

(b)

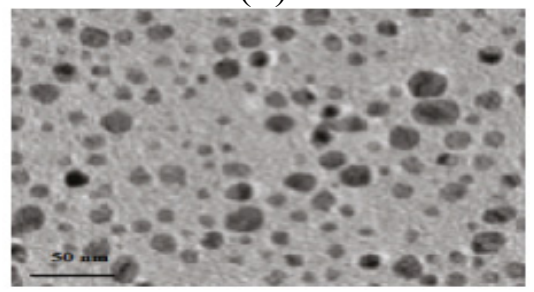

(d)

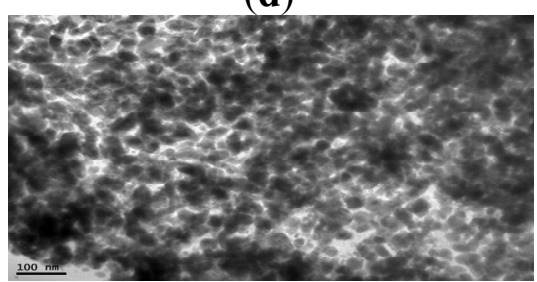

TEM microphotographs of the Ag NPs/PVA-SH synthesized with different amounts of PVA-SH were represented in Figure 9.

Figure 9. TEM micrographs of Ag NPs prepared with different amounts of PVA-SH (a) 0.5 , (b) 1 , (c) 2 and (d) 3 (Wt. \%).

(a)

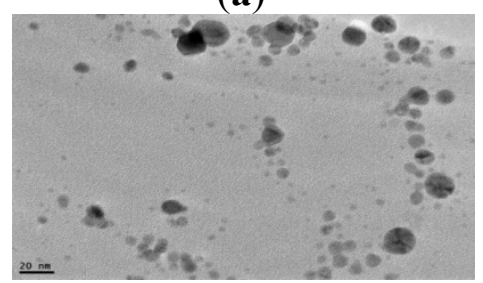

(c)

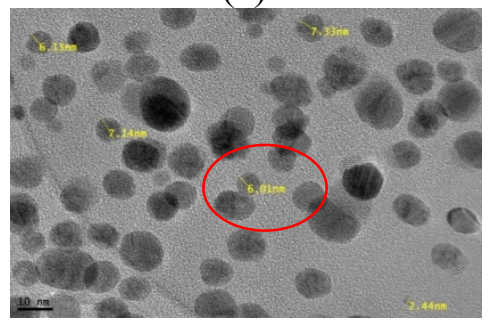

(b)

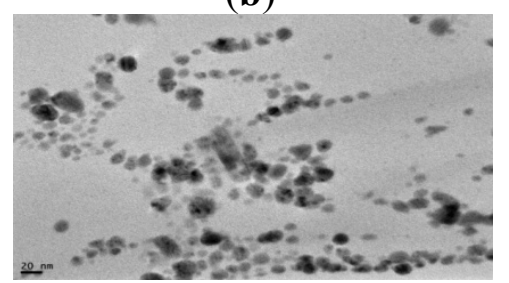

(d)

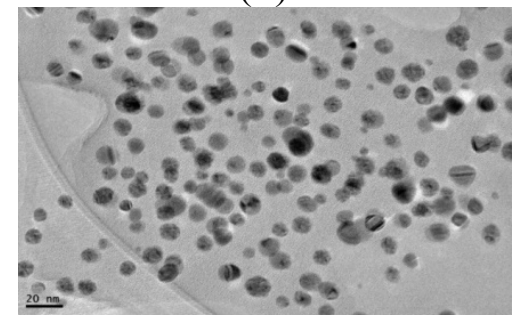

As can be seen from this figure, Ag NPs/PVA-SH the formation of monodisperse $\mathrm{Ag}$ NPs is affected by PVA-SH content. The amount of PVA-SH had a notable effect on the particle size and PSDs of the Ag/PVA-SH. It was also observed that the encapsulation of the Ag NPs in PVA-SH was successful, even at low concentration (0.5 Wt. \%). The numbers of Ag NPs encapsulated inside each particle are not the same. The average diameters and PDIs and PSDs of the different Ag NPs/PVA-SH compounds synthesized are listed in Table 1 and shown in Figure 10, respectively. 
Table 1. Average particle size diameters and polydispersity indices (PDI) obtained from the particle size distribution based on TEM of the Ag NP capped with PVA-SH.

\begin{tabular}{ccccc}
\hline Sample & dn (nm) & dw (nm) & dv (nm) & PDI \\
\hline Ag/PVA-SH 0.5 & 4.1 & 7.9 & 5.15 & 1.920 \\
Ag/PVA-SH 1 & 15.1 & 25.5 & 17.3 & 1.686 \\
Ag/PVA-SH 2 & 10.9 & 16.2 & 12.3 & 1.476 \\
Ag/PVA-SH 3 & 7.7 & 8.3 & 7.9 & 1.081 \\
\hline
\end{tabular}

Figure 10. Particle size distribution of Ag NPs prepared with different amounts of PVA-SH (a) 0.5, (b) 1, (c) 2 and (d) 3 (Wt. \%).
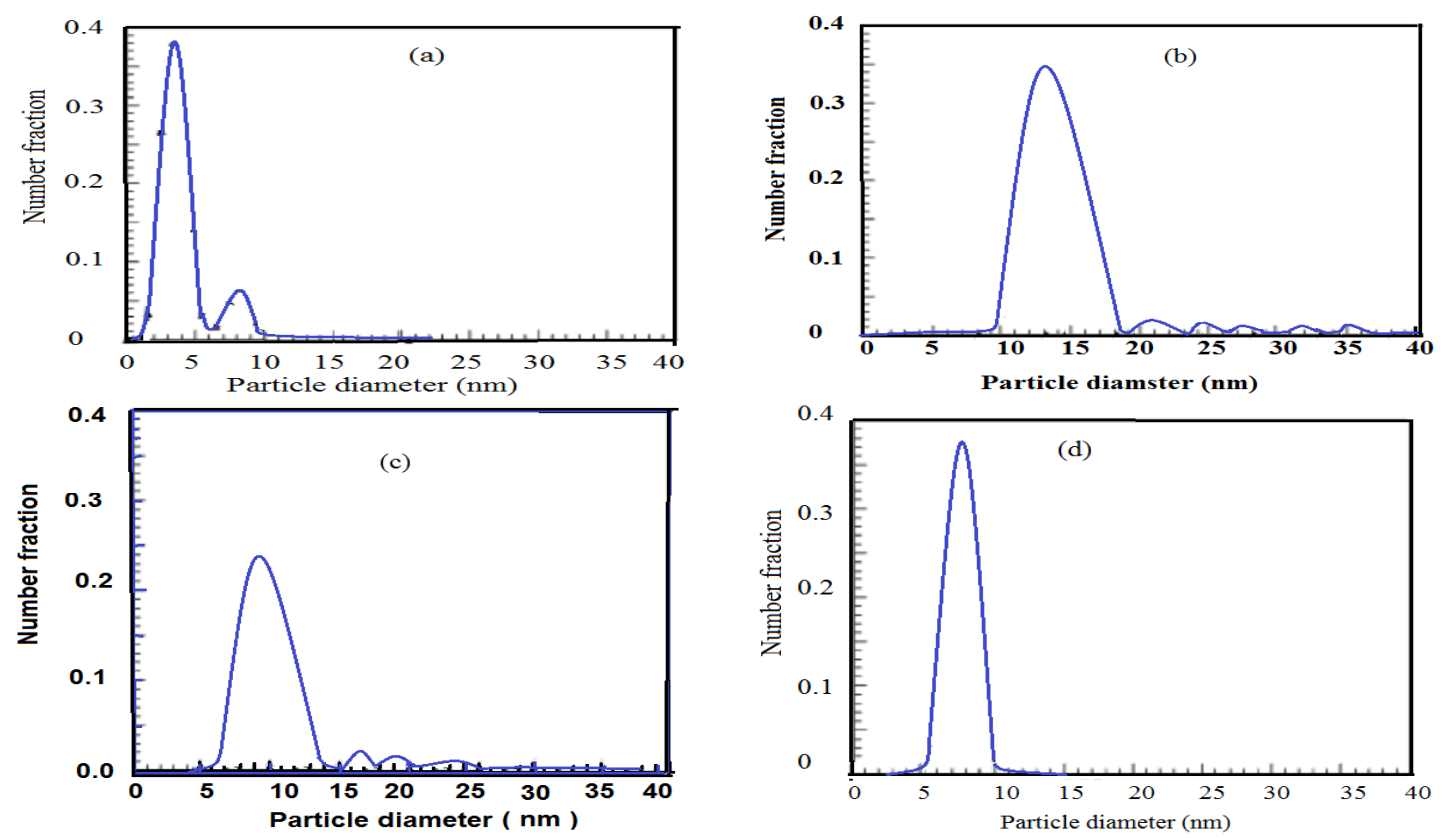

Careful inspection of data indicated that particle sizes and PDIs decreased, and PSDs became narrower when the amount of PVA-SH increased up to 3\%. Moreover, the PSD of Ag Nps/PVA-SH 3 was relatively narrow, and its PDI (1.081) was close to monodispersity in size (PDI < 1.05). However, at 0.5 (Wt. \%) of PVA-SH, the particle size of the Ag Nps/PVA-SH decreased, but the PSD was 1.920 and very broad (PDI), presenting a clear bimodality. This can be attributed to the generation of a high amount of Ag NPs which encapsulated in small amount of PVA-SH by the homogeneous nucleation mechanism. The distribution of Ag NPs inside PVA-SH particles is an important factor, which can influence the chemical stability of particles. As can be seen in the micrographs illustrated in Figure 8, in all the synthesized Ag Nps/PVA-SH the Ag NPs are mainly in the core of the PVA-SH particles.

The DLS data indicate that the average particle sizes obtained using this technique are much larger than those obtained using TEM. This is because even in the absence of any external magnetic field, the magnetostatic (magnetic dipole-dipole) interactions between the particles can cause their agglomeration. It has been determined experimentally [43], as well as from Monte Carlo simulations, that the particles form closed rings and long open loops with no particular spatial orientation due to magnetostatic interactions in the absence of any external magnetic field, and form long chains parallel to the applied field in the presence of an external field. The chains or loops have a lower diffusion coefficient than single particles. The equivalent sphere diameter measured using light scattering is 
greater than the elementary particle size as revealed from other techniques (such as XRD and TEM). The agglomerated ring and loop structures are not seen in TEM imaging, possibly because they are disturbed due to the drying forces present during TEM sample preparation. Moreover, DLS investigates the hydrodynamic diameter of the particles in solution which is based on the Brownian motion of the particles in the water. The hydrodynamic diameter of a particle in a specific solvent is dependent on the temperature, viscosity, and the translational diffusion coefficient of the particles. However, the hydrodynamic diameter measures all molecular size included stabilizer and hydration layer of water molecules.

XRD shows that the product prepared consisted of metallic Ag with a cubic structure. The broadening of peaks indicates very small sizes of $\mathrm{Ag}$ crystallites. X-ray diffraction patterns for Ag Nps/PVA-SH3 coated, before and after exposure to $1 \mathrm{M} \mathrm{HCl}$, were presented in Figure 11.

Figure 11. XRD patterns of AgNP coated with PVASH after exposure to $1 \mathrm{M} \mathrm{HCl}$ and $0.4 \mathrm{M}$ of glycine after (a) 1 week, (b) 1 month and (c) 3 months.

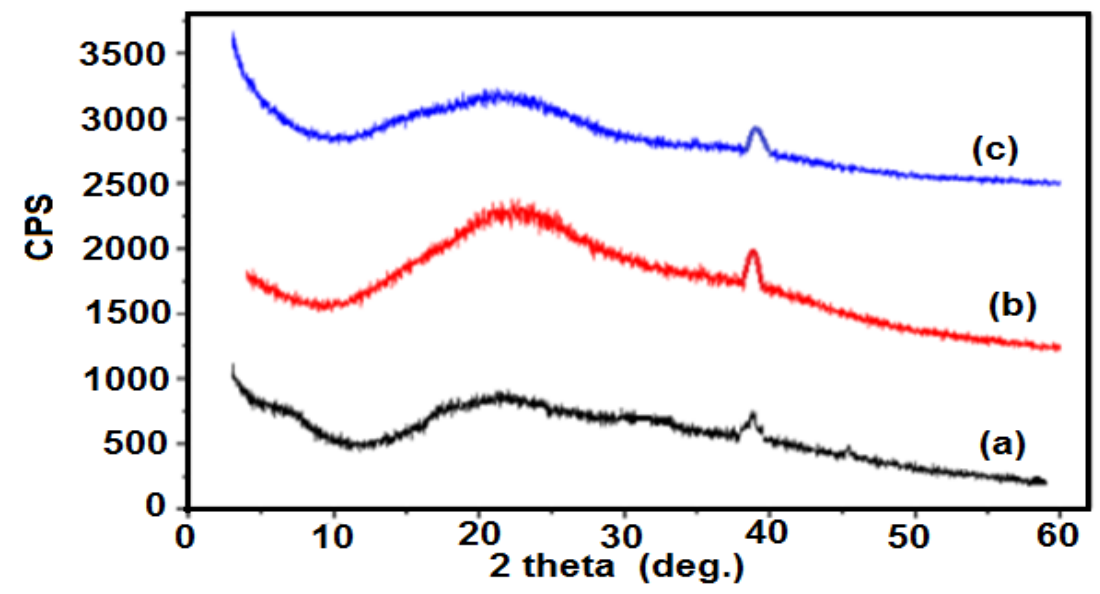

The data showed that the bulk structure of the compositions contained a polymeric amorphous phase, evident in WAXS profiles by two diffusive overlapped maxima at (2-theta) 15.8 and 21.8, and crystalline Ag nanoparticles, that was confirmed by characteristic crystalline peaks of silver (111) at (2-theta) 38.8. The appearance of these peaks indicated the formation of crystalline Ag nanoparticles with a tetragonal face-centered cubic lattice [44]. The data indicated that the present work succeeded in producing highly stable silver nanoparticles in $1 \mathrm{M} \mathrm{HCl}$ which have not been reported elsewhere in the literature. Moreover, this data indicated that the prepared Ag Nps/PVA-SH can be applied in the field of medical engineering and bio-analytical applications for the detection of proteins because their high resistance to SSF.

\section{Experimental Section}

\subsection{Materials}

Silver nitrate, trisodium citrate, poly(vinyl alcohol) (PVA, molecular weight $80,000 \mathrm{~g} \mathrm{~mol}^{-1}$ and $88 \%$ degree of hydrolysis) $p$-toluenesulfonyl chloride; triethylamine and thiourea were obtained from Aldrich Chemical Co. (St. Louis, MO, USA) and were used without purification. All reagents used in 
this experiment were analytical grade chemicals. The synthetic stomach fluid (SSF) was prepared using deionized distilled (DDI) water, $\mathrm{HCl}(0.42 \mathrm{M})$ and glycine $(0.40 \mathrm{M})$ to maintain the $\mathrm{pH}$ at 1.5 .

\subsection{Techniques}

\subsubsection{Synthesis of Poly(Vinyl Alcohol)-Thiol (PVA-SH)}

Partially hydrolyzed PVA (0.25 mol) was dissolved in DMSO and DMF (100 mL, 1:1 volume ratio) at $65{ }^{\circ} \mathrm{C}$. The reaction mixture was cooled to room temperature and triethylamine $(18.35 \mathrm{~mL})$ was added with stirring. $p$-Toluenesulfonyl chloride $(0.25 \mathrm{~mol})$ dissolved in DMF $(100 \mathrm{~mL})$ was then added dropwise at $10{ }^{\circ} \mathrm{C}$ (ice bath) over $30 \mathrm{~min}$. The mixture was then stirred overnight at room temperature. The reaction mixture was then poured into methanol to precipitate the poly(vinyl tosylate). The precipitate washed with methanol and dried at room temperature. Poly(vinyl tosylate), $(0.1 \mathrm{~mol})$ dissolved in water $(100 \mathrm{~mL})$ was mixed with a solution of thiourea $(0.11 \mathrm{~mol})$ in water $(30 \mathrm{~mL})$ and refluxed for $24 \mathrm{~h}$ at $90-100{ }^{\circ} \mathrm{C}$. The reaction mixture was cooled and $2 \mathrm{M} \mathrm{NaOH}(50 \mathrm{~mL})$ was added to the reaction mixture which was then refluxed for $3 \mathrm{~h}$ under a nitrogen atmosphere. The $\mathrm{pH}$ of reaction mixture was adjusted at $\mathrm{pH} 7$ with $0.1 \mathrm{M}$ aqueous $\mathrm{HCl}$ solution after cooling. The PVA-SH product was dried after precipitation of the reaction mixture into methanol. The yield was $88 \%$.

\subsubsection{Synthesis of Silver Nanoparticles}

Citrate-stabilized silver nanoparticles were prepared by dissolving silver nitrate $(0.09 \mathrm{~g})$ in water $(500 \mathrm{~mL})$ and heating at $90{ }^{\circ} \mathrm{C}$. A solution of $1 \%$ trisodium citrate $(10 \mathrm{~mL})$ was added under vigorous stirring. The solution was kept at temperature of $90{ }^{\circ} \mathrm{C}$ for $1 \mathrm{~h}$, to produce a golden yellow colour and then allowed to cool to room temperature. The silver nanoparticles were purified by ultracentrifugation (30 min at 30,000 rpm), followed by redispersion in water. The typical yield of citrate-stabilized silver nanoparticles was around $45 \%$ (with respect to silver). PVA-SH coated silver nanoparticles were synthesized by adding PVA-SH (1-3 g) to the silver nitrate solution. The reaction progressed as reported for citrate-stabilized silver nanoparticles. The reaction yields of PVA-SH-stabilized silver nanoparticles were 65,80 and $95 \%$ (with respect to silver) in the presence of 1,2 and $3 \mathrm{~g}$ of PVA-SH, respectively.

\subsection{Characterization of Ag NPS}

FTIR spectra were analyzed with a Nicolet FTIR spectrophotometer using $\mathrm{KBr}$ in a wavenumber range of 4,000-500 $\mathrm{cm}^{-1}$ with a resolution accuracy of $4 \mathrm{~cm}^{-1}$. All samples were ground and mixed with $\mathrm{KBr}$ and then pressed to form pellets. ${ }^{1} \mathrm{H}-\mathrm{NMR}$ spectra of the prepared polymers were recorded on a $400 \mathrm{MHz}$ Avance DRX-400 spectrometer (Bruker, Billerica, MA, USA). X-ray powder diffraction (XRD) patterns were recorded using a D/max $2550 \mathrm{~V}$ X-ray diffractometer (X'Pert, Philips, Eindhoven, The Netherlands). Transmission electron microscopy (TEM) micrographs were taken with a JEOL JEM-2100F (JEOL, Tokyo, Japan). A few drops of silver nanoparticle solution were diluted into $1 \mathrm{~mL}$ of ethanol, and the resulting ethanol solution was placed onto a carbon coated copper grid and allowed to evaporate. HR-TEM images of the nanocomposites were recorded using a JEM-2100F (JEOL) at an acceleration voltage of $200 \mathrm{kV}$. The TEM images were obtained at $25{ }^{\circ} \mathrm{C}$ with a TEM-100XS (JEOL, 
Tokyo, Japan) instrument. All images were acquired at a nominal magnification value of $66,000 \times$. This magnification of the microscope was calibrated with a NIST reference material (gold nanoparticles) which has reference values of the mean particle diameter as determined by TEM. This diameter is traceable to the SI meter as realized at NISTP. Calibration images were recorded at both sessions and combined for the final analysis of the scale factor. Image $\mathrm{J}$ software $\mathrm{v} 1.45 \mathrm{~s}$ was used for quantitative analysis of the TEM images of the reference material to obtain calibration information. Each image was thresholded to isolate the particles from the background. The resulting binary images were critically assessed, and any particles that overlapped, had ill-defined boundaries due to insufficient contrast or were only partially contained within an image were excluded from analysis. The area, measured in pixels, of the remaining particles was measured and this value was used to determine the equivalent diameter, measured in pixels, of a spherical particle with the same projected cross-sectional area (equivalent spherical diameter). A total of 10 images and 500 particles were analyzed. The particle size, actual number of particles, percentages by number, volume of particle $\left(\mathrm{V}=4 / 3 \pi \mathrm{r}^{3}\right)$, total volume of particles of each size and percentage by volume were calculated for each particle size (nm) from analysis. Samples for dynamic light scattering (DLS) were prepared by diluting several drops of the silver nanoparticle solution into $2 \mathrm{~mL}$ of water under vigorous stirring. The DLS measurements were performed on a Brookhaven Instruments system (Santa Barbara, CA, USA) with a $514.5 \mathrm{~nm}$ argon ion laser (model 85 Lexel Laser) as the light source. Ultraviolet-visible (UV-Vis) absorption spectra were obtained with a Techcomp UV2300 spectrophotometer ((Shanghai, China). Different concentrations of aqueous solutions of $\mathrm{HCl}(0.1 \mathrm{M}-1 \mathrm{M})$ and SSF were used to evaluate the stability of the synthesized Ag NPs.

\section{Conclusions}

The data generated in this study indicated that approximately of $40 \%$ of the $\mathrm{OH}$ group of PVA were converted to thiol $(\mathrm{SH})$ groups. The data with a simple in vitro model of the human stomach shows that citrate-stabilized Ag NPs agglomerate and partially react to form Ag Cl during exposure to SSF. New highly modified Ag nanoparticles prepared after coating with PVA-SH showed high dispersion and resistivity to $1 \mathrm{M} \mathrm{HCl}$ aqueous solution. TEM and XRD indicated that the stability of the prepared Ag nanoparticles toward hydrochloric acid increased with increasing PVA-SH contents up to 3 (Wt. \%). TEM indicated that the Ag NPs particle size and polydispersity decreased with increasing of PVA-SH content.

\section{Acknowledgments}

This project was supported by King Saud University, Deanship of Scientific Research, College of Sciences, Research Center.

\section{Author Contributions}

Ayman M. Atta suggested the research work and discussed the data, Hamad A. Al-lohedan discussed and supported the work and Abdelrahman O. Ezzat finalized the experimental work. 


\section{Conflicts of Interest}

The authors declare no conflict of interest.

\section{References}

1. Chen, A.; Chatterjee, S. Nanomaterials based electrochemical sensors for biomedical applications. Chem. Soc. Rev. 2013, 42, 5425-5438.

2. Amato, E.; Diaz-Fernandez, Y.A.; Taglietti, A.; Pallavicini, P.; Pasotti, L.; Cucca, L.; Milanese, C.; Grisoli, P.; Dacarro, C.; Fernandez-Hechavarria, J.M.; et al. Synthesis, characterization and antibacterial activity against gram positive and gram negative bacteria of biomimetically coated silver nanoparticles. Langmuir 2011, 27, 9165-9173.

3. Arvizo, R.R.; Bhattacharyya, S.; Kudgus, R.A.; Giri, K.; Bhattacharya, R.; Mukherjee, P. Intrinsic therapeutic applications of noble metal nanoparticles: Past, present and future. Chem. Soc. Rev. 2012, 41, 2943-2970.

4. Nadagouda, M.N.; Hoag, G.; Collins, J.; Varma, R.S. Green Synthesis of Au nanostructures at room temperature using biodegradable plant surfactants. Cryst. Growth Des. 2009, 9, 4979-4983.

5. White, J.M.L.; Powell, A.M.; Brady, K.; Russell-Jones, R. Severe generalized argyria secondary to ingestion of colloidal silver protein. Clin. Experiment Dermatol. 2003, 28, 254-256.

6. Chang, A.L.S.; Khosravi, V.; Egbert, B. A case of argyria after colloidal silver ingestion. J. Cutan. Pathol. 2006, 33, 809-811.

7. Wijnhoven, S.W.P.; Peijnenburg, W.J.G.M.; Herberts, C.A.; Hagens, W.I.; Oomen, A.G.; Heugenss, E.H.W. Nano-silver a review of available data and knowledge gaps in human and environmental risk assessment. Nanotoxicology 2009, 3, 109-138.

8. Schmähl, D.; Steinhoff, D. Versuche zur Krebserzeugung mit kolloidalen Silber-und Goldlosungen an Ratten [Experimental carcinogenesis in rats with colloidal silver and gold solutions]. Z. Krebsforsch. 1960, 63, 586-591.

9. Kim, Y.S.; Kim, J.S.; Cho, H.S.; Rha, S.D.; Kim, J.M.; Park, J.D. Twenty-eight-day oral toxicity, genotoxicity, and gender-related tissue distribution of silver nanoparticles in Sprague-Dawley rats. Inhalation Toxicol. 2008, 20, 575-583.

10. Evans, D.F.; Pye, G.; Bramley, R.; Clark, A.G.; Dyson, T.J.; Hardcastle, J.D. Measurement of gastrointestinal pH profiles in normal ambulant human subjects. Gut 1988, 29, 1035-1041.

11. McConnell, E.L.; Basit, A.W.; Murdan, S. Measurements of rat and mouse gastrointestinal pH, fluid and lymphoid tissue, and implications for in vivo experiments. J. Pharm. Pharmacol. 2008, 60, 63-70.

12. El Badawy, A.M.; Silva, R.G.; Morris, B.; Scheckel, K.G.; Suidan, M.T.; Tolaymat, T.M. Surface charge-dependent toxicity of silver nanoparticles. Environ. Sci. Technol. 2011, 45, 283-287.

13. Iravani, S. Green synthesis of metal nanoparticles using plants. Green Chem. 2011, 13, 2638-2650.

14. Njagi, E.C.; Huang, H.; Stafford, L.; Genuino, H.; Galindo, H.M.; Collins, J.B.; Hoag, G.E.; Suib, S.L. Biosynthesis of iron and silver nanoparticles at room temperature using aqueous sorghum bran extracts. Langmuir 2011, 27, 264-271. 
15. Bharde, A.A.; Parikh, R.Y.; Baidakova, M.; Jouen, S.; Hannoyer, B.; Enoki, T.; Prasad, B.L.V.; Shouche, Y.S.; Ogale, S.; Sastry, M. Bacteria-mediated precursor-dependent biosynthesis of superparamagnetic iron oxide and iron sulfide nanoparticles. Langmuir 2008, 24, 5787-5794.

16. Pillai, Z.S.; Kamat, P.V. What Factors Control the size and shape of silver nanoparticles in the citrate ion reduction method. J. Phys. Chem. B 2004, 108, 945-951.

17. Cheng, Y.; Yin, L.; Lin, S.; Wiesner, M.; Bernhardt, E.; Liu, J. Toxicity reduction of polymer-stabilized silver nanoparticles by sunlight. J. Phys. Chem. C 2011, 115, 4425-4432.

18. Chaikin, Y.; Bendikov, T.A.; Cohen, H.; Vaskevich, A.; Rubinstein, I. Phosphonate-stabilized silver nanoparticles: One-step synthesis and monolayer assembly. J. Mater. Chem. C 2013, 1, 3573-3583.

19. Cheng, F.; Betts, J.W.; Kelly, S.M.; Schaller, J.; Heinze, T. Synthesis and antibacterial effects of aqueous colloidal solutions of silver nanoparticles using aminocellulose as a combined reducing and capping reagent. Green Chem. 2013, 15, 989-998.

20. Salsamendi, M.; Cormack, P.A.G.; Graham, D. Template-directed synthesis of uniformly-sized silver nanoparticles with high colloidal stability. New J. Chem. 2013, 37, 3591-3594.

21. Chen, Z.; Zhang, X.; Cao, H.; Huang, Y. Chitosan-capped silver nanoparticles as a highly selective colorimetric probe for visual detection of aromatic ortho-trihydroxy phenols. Analyst 2013, 138, 2343-2349.

22. Roy, M.; Mukherjee, P.; Mandal, B.P.; Sharma, R.K.; Tyagi, A.K.; Kale, S.P. Biomimetic synthesis of nanocrystalline silver sol using cysteine: Stability aspects and antibacterial activities. RSC Adv. 2012, 2, 6496-6503.

23. Yuan, X.; Wen, S.; Shen, M.; Shi, X. Dendrimer-stabilized silver nanoparticles enable efficient colorimetric sensing of mercury ions in aqueous solution. Anal. Methods 2013, 5, 5486-5492.

24. Moonen, P.F.; Bat, E.; Voorthuijzen, W.P.; Huskens, J. Soft-lithographic patterning of room temperature sintering Ag nanoparticles on foil3. RSC Adv. 2013, 3, 18498-18505.

25. Taglietti, A.; Diaz Fernandez, Y.A.; Amato, E.; Cucca, L.; Dacarro, G.; Grisoli, P.; Antibacterial activity of glutathione-coated silver nanoparticles against Gram positive and Gram negative bacteria. Langmuir 2012, 28, 8140-8148.

26. Yonezawa, T.; Yasui, K.; Kimizuka, N. Controlled formation of smaller gold nanoparticles by the use of four-chained disulfide stabilizer. Langmuir 2001, 17, 271-273.

27. Li, X.M.; de Jong, M.R.; Inoue, K.; Shinkai, S.; Huskens, J.; Reinhoudt, D.N. Formation of gold colloids using thioether derivatives as stabilizing ligands. J. Mater. Chem. 2001, 11, 1919-1923.

28. Shelley, E.J.; Ryan, D.; Johnson, S.R.; Couillard, M.; Fitzmaurice, D.; Nellist, P.D.; Chen, Y.; Palmer, R.E.; Preece, J.A. Dialkyl sulfides: Novel passivating agents for gold nanoparticles. Langmuir 2002, 18, 1791-1795.

29. Shankar, S.S.; Rai, A.; Ahmad, A.; Sastry, M. Rapid synthesis of Au, Ag, and bimetallic Au core-Ag shell nanoparticles using neem (Azadirachta indica) leaf broth. J. Colloid Interface Sci. 2004, 275, 496-502.

30. Nadagouda, M.N.; Varma, R.S. Green synthesis of silver and palladium nanoparticles at room temperature using coffee and tea extract. Green Chem. 2008, 10, 859-862.

31. Yin, B.; Ma, H.; Wang, S.; Chen, S. Electrochemical synthesis of silver nanoparticles under protection of poly( $N$-vinylpyrrolidone). J. Phys. Chem. B 2003, 107, 8898-8904. 
32. Kvítek, L.; Panáček, A.; Soukupova, J.; Kolár, M.; Večeřová, R.; Prucek, R.; Holecova, M.; Zbořil, R. Effect of surfactants and polymers on stability and antibacterial activity of silver nanoparticles (NPs). J. Phys. Chem. C 2008, 112, 5825-5834.

33. Clemenson, S.; David, L.; Espuche, E. Structure and morphology of nanocomposite films prepared from polyvinyl alcohol and silver nitrate: Influence of thermal treatment. J. Polym. Sci. Part A Polym. Chem. 2007, 45, 2657-2672.

34. Kittler, S.; Greulich, C.; Diendorf, J.; Koller, M.; Epple, M. Toxicity of silver nanoparticles increases during storage because of slow dissolution under release of silver ions. Chem. Mater. 2010, 22, 4548-4554.

35. Slocik, J.; Wright, D. Biomimetic mineralization of noble metal nanoclusters. Biomacromolecules 2003, 4, 1135-1141.

36. Graf, P.; Mantion, A.; Foelske, A.; Shkilnyy, A.; Masic, A.; Thunemann, A.E.; Taubert, A. Peptide-coated silver nanoparticles: Synthesis, surface chemistry, and $\mathrm{pH}$-triggered, reversible assembly into particle assemblies. Chem. Eur. J. 2009, 15, 5831-5844.

37. Simpson, C.A.; Huffman, B.J.; Gerdon, A.E.; Cliffel, D.E. Unexpected toxicity of monolayer protected gold clusters eliminated by peg-thiol place exchange reactions. Chem. Res. Toxicol. 2010, 23, 1608-1616.

38. Atta, A.M.; Allohedan, H.A.; Ezat, A.; Issa, Z.A. Synthesis of Stabilized Silver Nanoparticles Exposed to Hydrochloric Acid. In Proceedings of the Technology Conference \& Expo, Washington, DC, USA, 12-16 May 2013; pp. 12-16.

39. Li, X.; Lenhart, J.J. Aggregation and dissolution of silver nanoparticles in natural surface water. Environ. Sci. Technol. 2012, 46, 5378-5386.

40. Choi, M.; Shin, K.H.; Jang, J. Plasmonic photocatalytic system using silver chloride/silver nanostructures under visible light. J. Colloid Interface Sci. 2010, 341, 83-87.

41. Diaz-Fernandez, Y.A.; Pallavicini, P.; Pasotti, L.; Milanese, C.; Pellicer, E.; Baró, M.D.; Ren, Y.; Malavasi, L. Nanoscale phase separation in coated Ag nanoparticles. Nanoscale 2011, 3, 4220-4225.

42. Rogers, K.R.; Bradham, K.; Tolaymat, T.; Thomas, D.J.; Hartmann, T.; Ma, L.; Williams, A. Alterations in physical state of silver nanoparticles exposed to synthetic human stomach fluid. Sci. Total Environ. 2012, 420, 334-339.

43. Maity, D.; Agrawal, D.C. Synthesis of iron oxide nanoparticles under oxidizing environment and their stabilization in aqueous and non-aqueous media. J. Magn. Magn. Mater. 2007, 308, 46-55.

44. Yamamoto, M.; Nakamoto, M. Novel preparation of monodispersed silver nanoparticles via amine adducts derived from insoluble silver myristate in tertiary alkylamine. J. Mater. Chem. 2003, 13, 2064-2065.

Sample Availability: Samples of PVA-SH and PVA-SH-stabilized silver nanoparticles are available from the authors.

(C) 2014 by the authors; licensee MDPI, Basel, Switzerland. This article is an open access article distributed under the terms and conditions of the Creative Commons Attribution license (http://creativecommons.org/licenses/by/3.0/). 